\title{
Characterization and modeling of the complete volcanic gas phase
}

\author{
François Le Guern ${ }^{1}$, Bertrand Cheynet ${ }^{2}$ and René Xavier Faivre-Pierret ${ }^{3}$ \\ CNRS, CFR 91190 Gif sur Yvette', \\ Thermodata, Domaine universitaire de Grenoble, \\ B.P. 66-38402 Saint Martin d'Hères Cedex ${ }^{2}$ and \\ Institut de Protection et de Sûreté Nucléaire. C.E.A. CENG avenue des Martyrs \\ 38000 Grenoble $^{3}$, France
}

(Received December 18, 1992; Accepted June 2, 1993)

\begin{abstract}
During the survey on the eruption of the volcano "La Soufrière de la Guadeloupe" (French West Indies), the behaviour of sulfur in volcanic gases was examined. Matsuo (1962) studied chemical equilibrium in volcanic gases which led us to develop the "in situ" gas analysis. A field gas chromatograph allowed direct injection of hot gases, before water and sulfur condensation occurred. A silica tube equipped with thermocouples was used for sublimates sampling and for measuring the condensation temperature. Conventional condensors and caustic soda bottles were used for sampling and later complementary analyses in the laboratory. A free energy minimisation computational method modelled the physical and chemical changes that occurred during cooling of volcanic gases. The high temperature composition of the gas mixture was recalculated from the concentrations of the gaseous and solid components obtained during sampling. The equilibrium composition was first calculated at the collection temperature for 22 elements. The model then calculated the equilibrium compositions at $50^{\circ} \mathrm{C}$ intervals using the residual gas composition after condensation at the previous temperature. The depositional sequence observed in the silica tube depend on the temperature and the concentration of elements in the initial mixture. The computational method was applied to gases sampled from Mt. St Helens. The calculated results agree with observed sublimates. A new method for volcano monitoring is proposed which allow to determine the magmatic origin of volcanic gases and their emission temperature from remote plume analysis. The model is also applicable to estimate the temperature and the composition of the gases entering hydrothermal systems or participating in ore deposits in the basement of the volcano. The model predicts the behaviour of the main and minor species emitted in the volcanic gases. This approach is not only restricted to the volcanic gas studies but can be applied to studies of high temperature reactive gas reactor to simulate cooling reactions.
\end{abstract}

\section{INTRODUCTION}

Volcanologists have been trying, for years, to reconstruct the initial composition of the volcanic gas, but this was difficult because the volcanic gas composition was modified by reactions that occurred along the sampling line, and in the sample bottles during transportation, storage and transfer before the analysis. The quality of sampling varied and in many cases, it was impossible to resample the same fumarole, because the site was remote or dangerous and the volcanic activity changed. The classical method used for interpreting the results of the survey of the Soufrière of La Guadeloupe (French West Indies) was a model in which $\mathrm{SO}_{2}$ was regarded as magmatic and $\mathrm{H}_{2} \mathrm{~S}$ was hydrothermal in origin. This model was based on an interpretation of an Ellingham diagram (Sabroux, 1979) and an analogy of the magmatic gases collected on the lava Lake at Erta Ale (Ethiopia) where $\mathrm{SO}_{2} / \mathrm{H}_{2} \mathrm{~S}$ partial pressure ratio was more than 100 (Giggenbach and Le Guern, 1976). It was also assumed that acid lavas such as andesites should be 
"more oxidizing" than tholeites (Sabroux and Zettwoog, 1977).

On the 17 and 18 September 1977, eleven weeks after the end of surface phreatic eruptions, one of the authors (FLG) was collecting volcanic gases from the summit fractures at La Soufrière. The gases were analysed a few hours later in the local observatory and showed very sharp random daily variations from pure $\mathrm{H}_{2} \mathrm{~S}$ to pure $\mathrm{SO}_{2}$. Phenomenology, geochemical and geophysical observations did not indicate any change in volcanic activity so we decided to reconsider the methods of collection and analysis of the volcanic gases.

Matsuo (1962) published a paper describing the presence of $\mathrm{H}_{2} \mathrm{~S}$ in the magmatic gases of Kilauea (Hawaii). He predicted that the sulfur gas equilibrium changed when the volcanic gas mixture cooled below $130^{\circ} \mathrm{C}$. This paper gave us the idea to design a field gas chromatograph, which analyse volcanic gas samples in the field before they completely cool and condense.

This method was tested on different eruptive volcanoes, where $\mathrm{H}_{2} \mathrm{~S}$ was found in magmatic gases. The theoretical predictions made by Matsuo (1962) were confirmed experimentally and we could successfully rebuild the analytical method and computer modeling.

\section{The Sampling Method}

Volcanic gases contain mainly $\mathrm{H}_{2} \mathrm{O}$ (99.9 to $50 \%$ of the total gas phase), which condense below $100^{\circ} \mathrm{C}$, and lesser $\mathrm{CO}_{2}, \mathrm{SO}_{2}, \mathrm{H}_{2} \mathrm{~S}, \mathrm{COS}$, $\mathrm{CH}_{4}, \mathrm{H}_{2}, \mathrm{CO}, \mathrm{Ar}, \mathrm{N}_{2}, \mathrm{HCl}$ and $\mathrm{HF}$, which consist of 90 to $99 \%$ of the remaining "dry gases". Classically only these major compounds were taken into account by volcanologists. They were sometimes analysed in the field (Jaggar, 1917; Tazieff and Tonani, 1963; Elskens et al., 1969; Tonani, 1971; Iwasaki, 1971). Generally acid gases was absorbed in alkaline solution in the field in order to prevent the chemical reaction during the transportation and the storage. Usually the absorbed gases in alkaline solution are analysed in the laboratory by classical "wet analysis" techniques (Giggenbach 1975). The residual free "dry gases" were sometimes analysed by mass spectrometry but most generally by gas chromatography. The gas chromatography was adjusted many times to obtain accurate analysis (Naughton et al. 1963; Elskens et al. 1969).

The alkali and metal content of volcanic gases is generally so low (four to five orders of magnitude less than in $\mathrm{S}, \mathrm{Cl}$ and $\mathrm{F}$ ) that the amount of sulfur, chlorine or fluorine loss by condensation with metals in the sampling line is usually not detected by the classical analysis. At about $130^{\circ} \mathrm{C}$, reaction between $\mathrm{H}_{2} \mathrm{~S}$ and $\mathrm{SO}_{2}$ occurs as described by Matsuo (1962) and most of sulfur then precipitate. At $100^{\circ} \mathrm{C}_{2} \mathrm{O}$ condenses and dissolves the acid gases to form a very low $\mathrm{pH}$ solution. As a result of these transformations, three phases (solid, liquid and gas) form. The usual analytical methods cannot give the complete initial gas composition because the aerosols and condensates are not quantitatively taken into account.

A new method of sampling and analysis of volcanic gas was developed to overcome these condensation problems. A silica tube was inserted into a fumarole for sublimate and gas sampling. The gases were diverted to other sampling devices at the tube outlet (Le Guern and Bernard, 1982 a). A field gas chromatograph was specially designed to analyse as many components as possible (Le Guern and Gerlach 1979). Evacuated sampling bottles containing caustic soda solution (caustic soda bottle) were used to dose $\mathrm{Cl}$ and $\mathrm{F}$, not determined by the chromatograph (Giggenbach 1975). The condensate collected in a specially designed condenser (Chevrier and Le Guern 1982) was analyzed for the minor elements (halogens, alkalines, metals.) (Fig. 1)

\section{The Sublimate Sampling}

In the past, sublimates and condensates were studied separately from the major components of the gas phase. Since the conditions of sublimates formation in the ground was not stable and not measured, only the sublimates forms and composition were described 


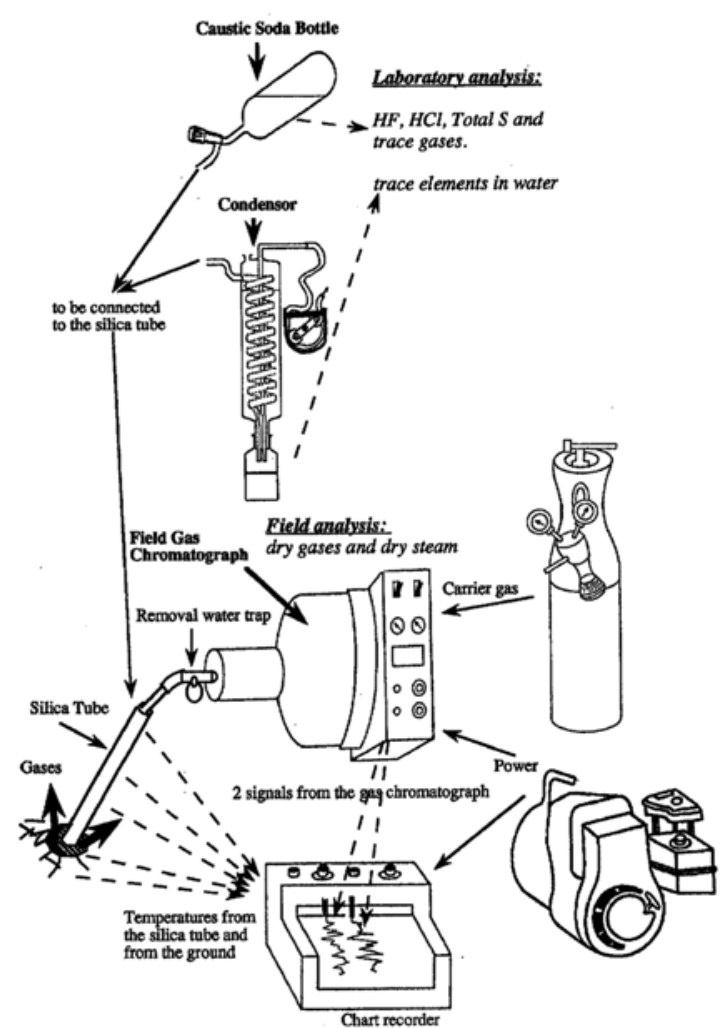

Fig. 1. Diagram showing the sampling equipement used in the field. The analytical procedures have been previously described: caustic soda bottles (Giggenbach 1975), condensor (Chevrier and Le Guern 1982), silica tube and field gas chromatograph (Le Guern and Bernard 1982 and $b$; Le Guern and Gerlach 1979; Le Guern et al. 1982 a; Le Guern 1988).

(Naughton et al. 1974).

In order to overcome these problems a new method for sampling sublimates in a silica tube was developed (Le Guern and Bernard, 1982 a and b; Bernard and Le Guern 1986). A silica tube was inserted in a fumarole as deep as possible to prevent back diffusion of atmospheric gases. This tube was left standing until the naturally flowing volcanic gas cover the inner tube wall with sublimates. Three to ten thermocouples are fixed on the outer tube wall, continuously measuring the temperature of the surface where the sublimates form. A standard length of one meter was used in order to make transportation easy. Two or three elements can be attached to make a longer sampling line. The usual diameter is two to three $\mathrm{cm}$. This method allows collection of sublimates in the absence of air oxidation, and it also provide information on the temperature of deposition and the composition of the volcanic gas from which the sublimates deposited. Natural sublimates were also collected in the ground in order to check that the composition of the samples studied was not induced by the collection devices.

Thermal gradient in the tube: The tube was heated by the volcanic gas discharge and cooled by radiation and air convection in the atmosphere. This cooling of the tube wall also affected the volcanic gas flow through the tube. The temperature gradient is not uniform along the tube and vary depending on the gas flow rate, the initial fumarole temperature and the position of the tube in the gas stream.

Measurements made in the field with the $\mathrm{f}_{\mathrm{O}_{2}}$ probe or with the field gas chromatograph allowed the detection of air. A large flow rate of volcanic gases reduced back diffusion of the atmosphere in the ground to less than $10^{-5}$ atmosphere as measured in the field using the field gas chromatograph or chemical sensors (Gantes et al. 1983; Le Guern, 1988). This very low contamination was confirmed by thermodynamic calculation of the disequilibrium induced by atmospheric oxidation (Gerlach and Casadevall, 1986).

Flow rate in the tube: Several experiments showed that only a small part of sublimates was trapped on the tube walls, and most of them escaped to the atmosphere as aerosols. Samples collected at the outlet of the tube were a mixture of uncondensable gases and aerosols of water droplets and the solid particles, which were similar to the sublimates observed on the tube wall. It was experimentally determined that the proportion of sublimates trapped on the tube wall depended upon the velocity of volcanic gases (Charuau, 1982). Although the tube collects enough particles to make the analysis possible, the main part of particles was not trapped in the tube. When the gas velocity is too fast, only a 
small amount of sublimates will be attached on the tube wall, and the outlet temperature will be too high to allow low temperature sublimates be collected on the tube wall. When the gas velocity is very small, most of the aerosols will be trapped on the tube wall and the samples collected at the tube outlet will give results non-representative of the initial gas composition.

Tests were made for nuclear reactors to evaluate the proportion of particle attaches to the tube wall along gas flow (Charuau, 1982) Using his results, we evaluated the efficiency of the method for the following two cases:

1) The amount of condensation that occurs by the cooling in the tube is very low: this is the case for volcanic gases when the outlet temperature of the tube is higher than $100^{\circ} \mathrm{C}$. Since the oxides, sulfur and sulfate concentration are 3 to 4 orders of magnitude less than the water content, the flow rate will be little affected by the condensation of any species except water. As a first approximation, we can consider the velocity as constant.

2) The amount of condensates occurring during sampling is important: this situation often happens in industrial reactors where one of the major components condense at high temperature. In such a case, the velocity of gas will decrease along the tube. For this case, we have developed a system continuously measuring the gas velocity in different places along the tube using probes measuring the changes in thermal conductivity (Le Guern, 1985).

For the volcanic gas sample containing 95 to 99 volume \% of water we have determined that less than $5 \%$ of the condensed material was trapped along the sampling line: more than $95 \%$ escaped out from the tube outlet as gases and aerosols. (Le Guern 1988).

Identification of sublimates: In the laboratory the silica tubes are cut and deposits are collected. In some cases, the deposits are dissolved in $\mathrm{CCl}_{4}$, $\mathrm{HCl}$ or $\mathrm{H}_{2} \mathrm{O}$ in order to concentrate minor species. Then identification and analysis were made by X-ray diffraction, scanning electron microscope and electron microprobe (Jedwab,
1975; Le Guern and Bernard, 1982 a; Bernard, 1985; Bernard and Le Guern, 1986).

\section{The Field Gas Chromatograph}

A field gas chromatograph was designed for the analysis of volcanic gases (Le Guern and Gerlach, 1979; Le Guern et al., 1982 a and c). This chromatograph was connected to a small glass tube which was inserted into the silica tube $15 \mathrm{~cm}$ deep to prevent air contamination. "Dry gas" analysis was made by pumping the hot gases through a water trap: a small vessel containing $\mathrm{P}_{2} \mathrm{O}_{5}$. After a few analyses of dehydrated gases, the water trap was removed and the hot gases were injected directly to the field gas chromatograph. Sampling flasks containing a calibrated mixture or samples collected a few seconds before were also analysed by the field gas chromatograph in the field. This method made it possible to evaluate the physical and chemical evolution of samples after the sampling.

The sample lines between the small glass tube and the analytical column in the field gas chromatograph has to be free of leaks. After testing different systems of injection, the preevacuated six ways valve system was adopted (Fig. 2).

Sample injection proceeded in 3 different steps:

1-The system was evacuated or purged by the sample gases.

2-Sample was introduced to the sampling loops and the pressure is recorded.

3-Rotating the valve, the carrier gas drives the sample to the column.

This method present numerous advantages: - preevacuation of the dead volumes

- easy measurement of the injected gas pressure - minimum atmospheric contamination -ability to inject samples at a pressure below atmosphere when sampling gases in a container -calibration by injection of known gas concentration in the same way during the measurements, making it possible to compensate for base line variations.

As it is not possible to separate $\mathrm{CO}_{2}, \mathrm{H}_{2} \mathrm{~S}$, $\mathrm{SO}_{2}, \mathrm{H}_{2} \mathrm{O}, \mathrm{H}_{2}, \mathrm{O}_{2}, \mathrm{~N}_{2}, \mathrm{CH}_{4}$, and $\mathrm{CO}$ on a single 


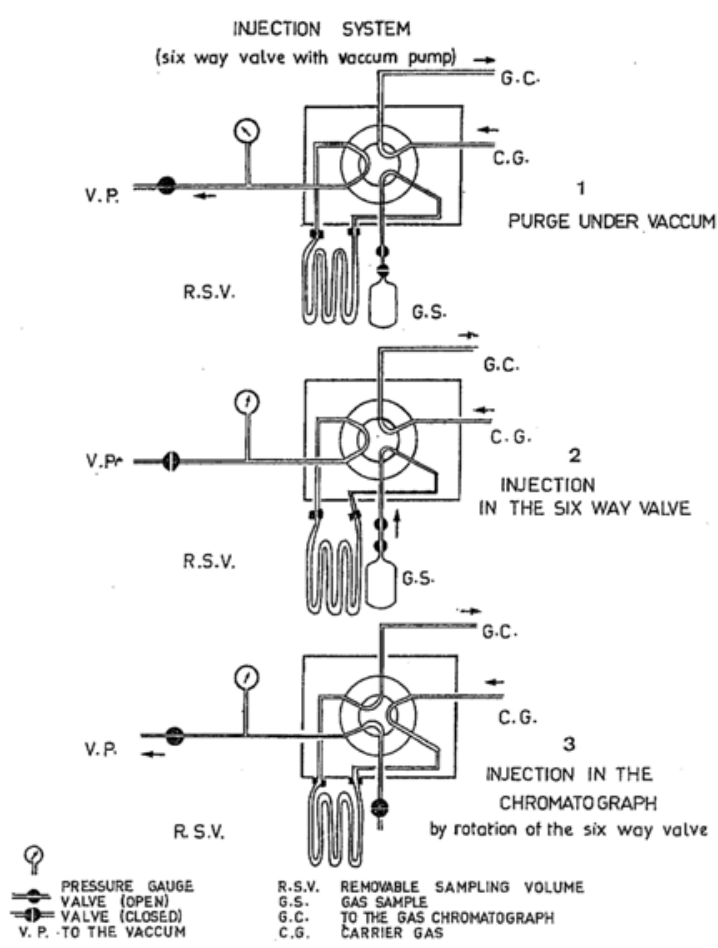

Fig. 2. The sample transfer to the analyser through a six-ways valve. Sample injection proceeded in 3 different steps: 1-the system was purged either by evacuation or by pumping throught with the sampled gases, 2-sample was introduced to the sampling loops, pressure was equilibrated and recorded, 3rotating the valve, the carrier gas drives the sample to the column.

column, two column were used in series. The Porapak or Chromosorb column was used for the separation of the "acid" gases, the molecular sieve second column separated $\mathrm{H}_{2}$, $\mathrm{O}_{2}+\mathrm{Ar}, \mathrm{N}_{2}, \mathrm{CH}_{4}$ and $\mathrm{CO}$. Helium was used as a carrier gas. The detection was made on a catharometer (thermal conductivity detector) sometimes associated with a flame ionisation detector (Fig. 3). The gas transfer in the analyser being made at $130^{\circ} \mathrm{C}$ : in "dry steam" no corrosion occur inside the system as we had previously observed in the fumaroles of Vulcano (Italy) (Le Guern et al., 1980 a). The system was designed to satisfy the following specifications:

-analysis was made in the field at a temperature over $130^{\circ} \mathrm{C}$, to prevent the $\mathrm{S}$ and $\mathrm{H}_{2} \mathrm{O}$ condensation -one injection make possible to detect the maximum number of constituents

-no corrosion occur in the system

-the system is able to analyse samples containing more than $99 \%$ of steam. (Le Guern et al. 1980).

\section{Results Obtained}

This method was applied to magmatic gases sampled from different volcanoes, (Le Guern and Gerlach, 1979; Le Guern and Bernard, 1982 a and b; Le Guern, 1988). Other volcanologists are now commonly using the silica tube method (Bernard, 1985; Symonds, 1985; Symonds et al., 1987). Results of the field gas chromatograph analysis obtained at Mt St Helens volcano are shown on Fig. 4. The complete list of results are shown on Fig. 5. The first tests in the fumaroles of Vulcano Island (Italy) confirmed that the field gas analysis does not transform the sulfur equilibrium (Le Guern and Faivre-Pierret, 1982). The method has been used on different volcanoes: Mt. Usu (Japan), Mt. Momotombo (Nicaragua), Mt. Merapi (Indonesia), Kilauea and Mt. St Helens (USA) (Le Guern and Bernard, 1982 a and b; Le Guern et al., 1982 a; Le Guern et al., 1982 b). The field gas chromatograph enables us to analyse toxic gases in mines or in the fields around volcanoes as in Dieng (Indonesia) or in Vulcano (Italy) (Le Guern et al., 1982 b; Tazieff et al., 1986). We also applied this new method to high temperature industrial reactors such as glass furnace, cars exhaust pipe gases and particularly in the industrial distillation of sulfur and radioactive wastes burning (Le Guern, 1988). Today the field gas chromatograph is made under license by a French company*.

When field and laboratory analyses were completed the concentration of major species and minor elements were combined with the results obtained and used to reconstruct a complete elemental gas composition.

*GIRA instrument and systems marketed by Chromato Sud 19, rue Nauville 33000 Bordeaux France tel (33) 56244649 . FAX (33) 56990147 


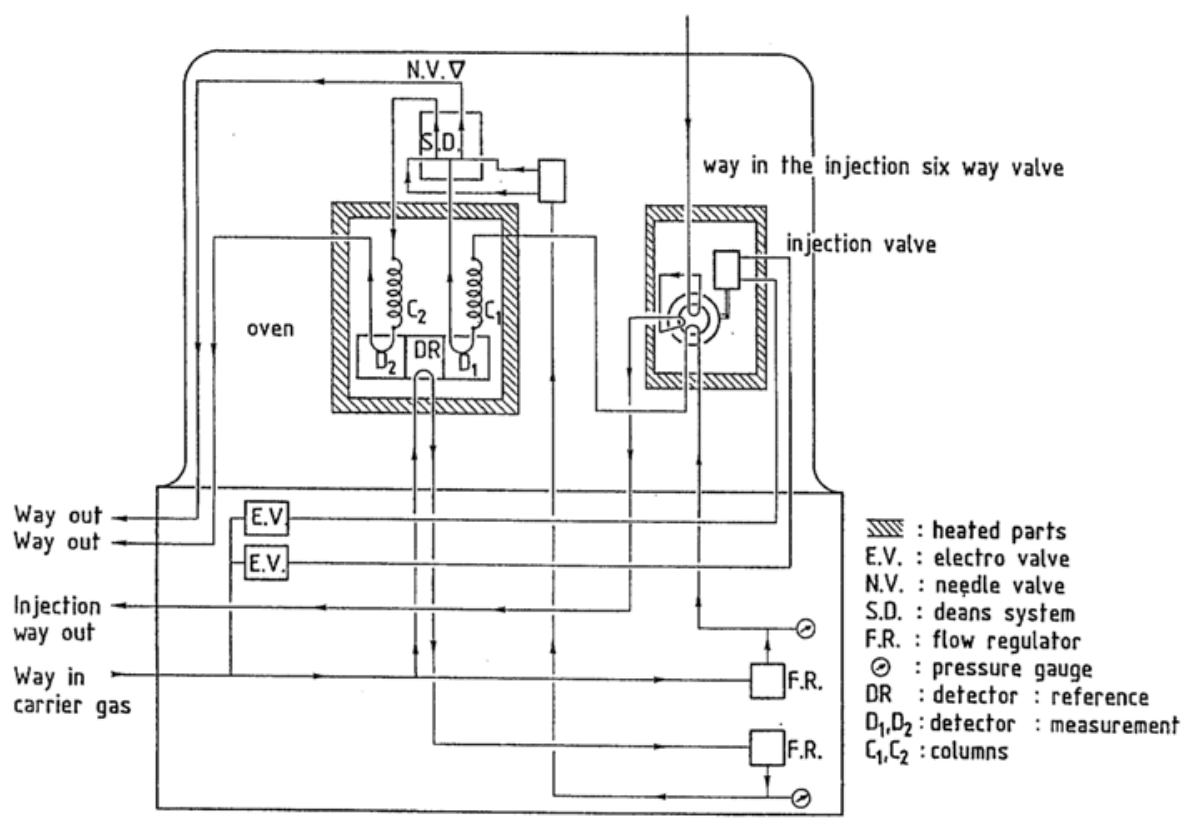

Fig. 3. The prototype of the field gas chromatograph.

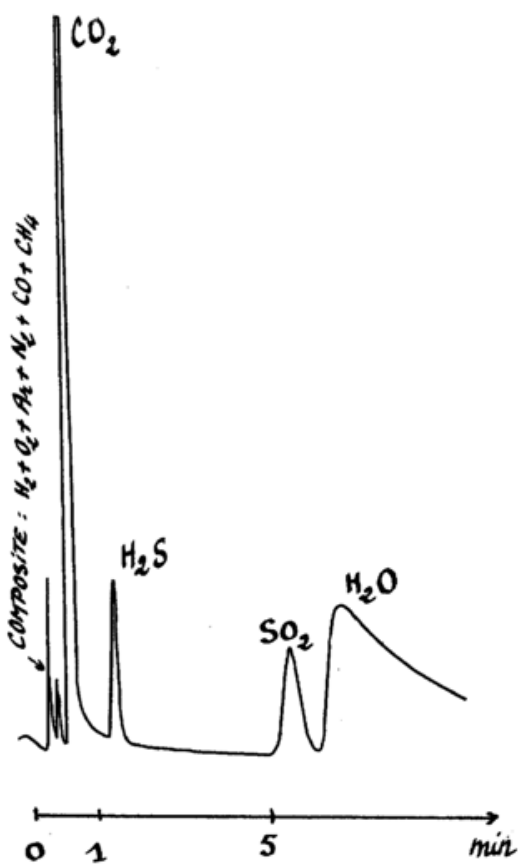

Fig. 4. Results obtained from the dry gases analysis at Mt. St Helens volcano September 161981.

\section{The Calculation Method}

Our new sampling method were applied to the magmatic gases escaping from the growing Dome of Mt. St Helens on September 16 and 17 1981 in cooperation with the U.S. Geological Survey.

Three sampling methods (field gas chromatograph, caustic soda bottle and condensor) permitted the concentration of more than 30 elements to be determined (Fig. 5). These elements can generate a great number of compounds that can participate in the reactions which occur during the cooling of volcanic gases. It is impossible to write down all the chemical reactions that can occur among these compounds but it could be a few thousand. The classical method based on the analysis of equilibrium reactions is completely inefficient.

A direct Gibbs energy minimisation method was used to compute complex chemical equilibria and condensation processes (Cheynet, 1978). A similar approach was applied to the major components of the volcanic gas phase (Heald and Naughton, 1962; Heald et al., 1963; Nordlie, 1971; Gerlach and Nordlie, 1975) and to a system including major and trace components of a volcanic system (Naughton et al., 1974). This method made it possible to 


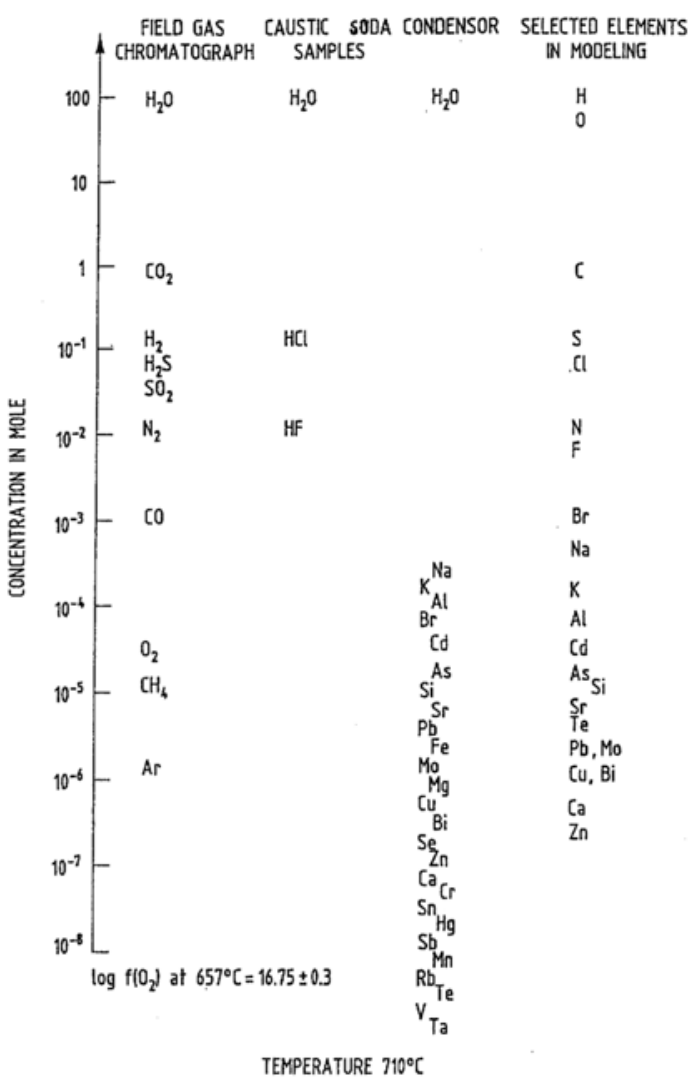

Fig. 5. Results obtained from the field gas chromatograph and complementary analysis in the the laboratory at Mt. St Helens volcano September 16 and 151981.

reconstruct the equilibrium composition of gas mixture at a high temperature from the initial atomic ratio and to recalculate the change of concentration of the gaseous and solid phases during cooling (Cheynet, 1985). Since the memory of the computer is limited, the number of elements used in modeling was reduced from more than 30 to 22 discarding very minor elements of which concentrations was below $10^{-7}$ mole \% (Fig. 5). The primary file contained the following elements: $\mathrm{C}, \mathrm{H}, \mathrm{O}, \mathrm{S}, \mathrm{N}, \mathrm{Cl}, \mathrm{F}, \mathrm{K}$, $\mathrm{Na}, \mathrm{Fe}, \mathrm{Zn}, \mathrm{As}, \mathrm{Pb}, \mathrm{Se}, \mathrm{Cd}, \mathrm{Bi}, \mathrm{Sb}, \mathrm{Cu}, \mathrm{Ca}, \mathrm{W}$, $\mathrm{Mo}$, and $\mathrm{Si}$. This file contained 778 inorganic compounds, and the complete list has been published (Le Guern, 1988). The equilibrium composition at the temperature of the fumarole was calculated as a first step. The selected 22 elements were introduced in the computer with

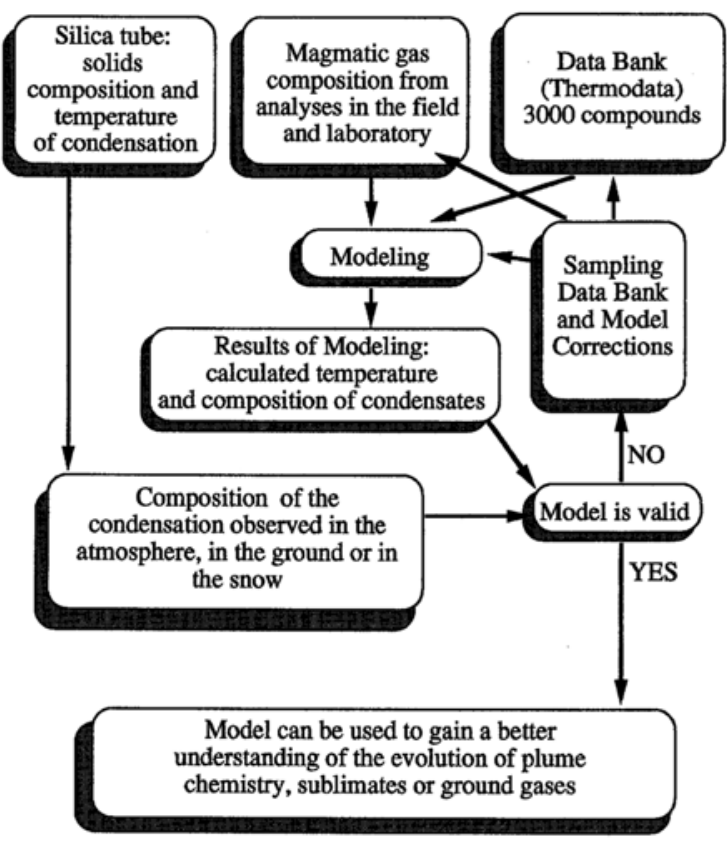

Fig. 6. Flow chart of the computional method.

their concentration in the volcanic gases. Then the equilibrium composition was calculated during cooling $50^{\circ} \mathrm{C}$ interval. At each step, the calculation started with the composition of the residual gas phase computed at the previous temperature, assuming that the solid phases that formed did not continue to react with the gases.

\section{Modeling}

To be representative for the natural system, the analytical data and the calculation needs to satisfy the following five conditions:

1 -The sample analysed must be free of any alterations such as contamination by atmosphere, organic matter and meteoric water, oxidation by the atmospheric oxygen, reaction of gases with the sampling devices, condensation and reevaporation in the sampling device, and analytical errors.

2-All the major species must be considered in the model.

3-The Data Bank must have a list of the main thermodynamic properties as a function of temperature: enthalpy of formation, entropy, specific heat, and heats of phase transition. 
These values must be reliable.

4-The calculation must converge, otherwise the equilibrium conditions of the system will not be well defined.

5-As the calculation is based on a system under equilibrium, the natural system should be close to equilibrium, otherwise no relationship will appear between the calculated and the observed situations.

The chemical composition and the temperature of sublimate deposition calculated by the computer were compared with the temperature and sublimates composition obtained from the silica tube analysis. If the chemical species were similar and if the calculated temperatures were close to the temperatures measured in the silica tube, the model was considered as representative. It has also been possible to compare the results of calculation with the incrustations, sublimates, condensates and aerosols collected in the atmosphere, on, and in the ground (Bernard and Le Guern, 1986). Figure 6 shows a flow chart for this method. These calculations require the elaboration of 17 files selected from the Data Bank to take into account the composition of sublimates formed from the gas phase.

The general trends between calculated and observed results were in good agreement but some disagreement arised (Fig. 7). Lead and cadmium sublimates were found on the tube wall, but calculation gave gaseous compounds at room temperature (Fig. 8A). In this case, the modeling could not reproduce the natural system. These two cases were carefully checked as follows.

Cadmium: In the case of cadmium, the data for formation enthalpy were taken from Mills (1974), which gave:

$$
\begin{aligned}
& \Delta \mathrm{H}_{\mathrm{f} 298}^{\circ} \mathrm{CdS}(\mathrm{s})=-35.7 \mathrm{kcal} \mathrm{mol} .^{-1} \\
& \Delta \mathrm{H}_{\mathrm{f} 298}^{\circ} \mathrm{CdS}(\mathrm{g})=-45.5 \mathrm{kcal} \mathrm{mol} .^{-1} .
\end{aligned}
$$

These values give gaseous cadmium sulfide stable at room temperature (Fig. 8A). This is in complete disagreement with the observations of CdS solid: Greenockite (CdS) was observed on the tube walls and also collected in the ground as
Solid phase observed only in the fumarolic incrustations:

$\begin{array}{ll}\mathrm{Ca}_{2}\left(\mathrm{Mo}_{0}<W\right) \mathrm{O}_{4} & \text { Powellite } \\ \mathrm{Pb}_{3} \mathrm{Bi}_{2} \mathrm{~S}_{6} & \text { Lillianite } \\ \mathrm{Pb}_{4} \mathrm{Bi}_{2} \mathrm{~S}_{7} & \text { Cannizzarite } \\ \mathrm{Fe}_{2} \mathrm{O}_{3} & \text { Hematite }\end{array}$

Solid phase observed in the silica tube and non obtained in calculations:

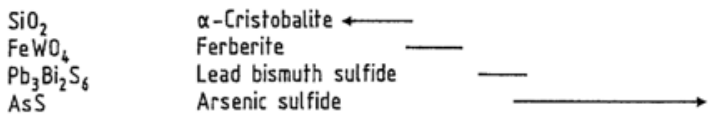

Solid phase observed in the tube and obtained in the calculations:

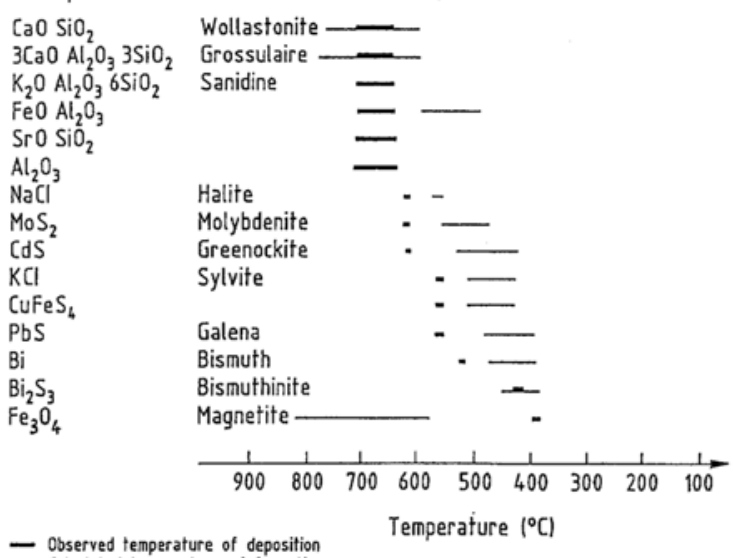

- Observed temperature of deposition

Fig. 7. Comparison of calculated and the results obtained analysing the deposits collected on the tube walls and the natural fumaroles incrustations collected at Mt. St Helens.

a natural sublimate at several volcanoes (Bernard, 1985). Occurrence of the natural sublimate also agrees with the sulphide condensation during the experimentation made in the laboratory (Ibuki, 1959).

When thermodynamic data are placed in a row by the homologous series or by the atomic numbers, a single systematic change in the row of numbers is often seen. However the formation enthalpy of CdS is out of the simple systematics in both following cases.

homologous series:

$$
\Delta \mathrm{H}_{\mathrm{f} 298}^{\circ} \mathrm{ZnS}(\mathrm{g})=+48.3 \mathrm{kcal} \mathrm{mole}^{-1}
$$

(Thermodata Bank ${ }^{\dagger}$ )

${ }^{\dagger}$ Thermodata Bank: B.P. 66-38402 Saint Martin d'Hères CEDEX France Tel (33) 76427690 

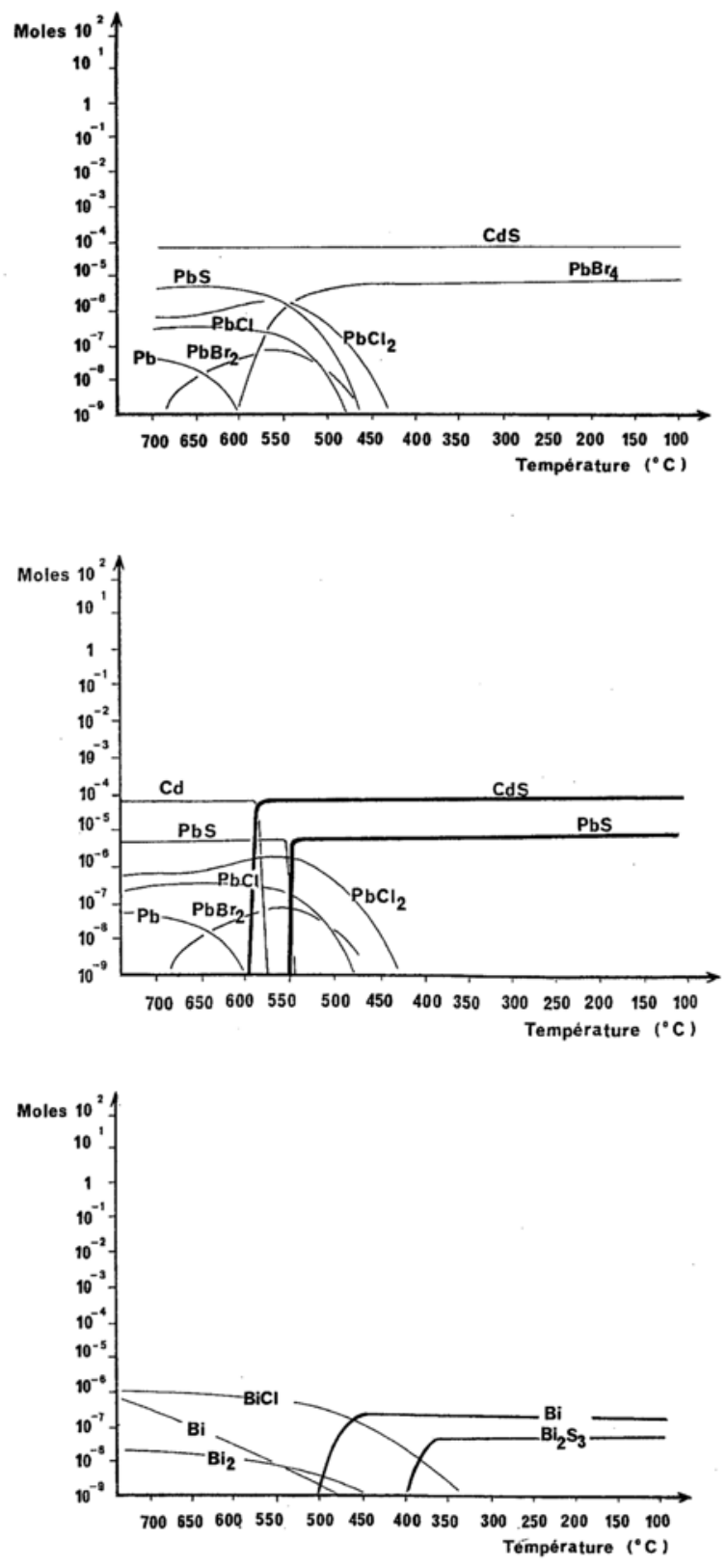

Fig. 8. The cadmium, lead and bismuth. behaviour: thin lines represent the gases, thick lines signify the solids formed by condensation. A) Lead and cadmium behaviour which was initialy calculated. B) Lead and cadmium behaviour after corrections according to the deposits observed in the silica tube. C) Bismuth behaviour: calculation shows a condensation of Bi gas as $\mathrm{Bi}$ solid but $\mathrm{BiCl}$ in the gas phase condense as $\mathrm{Bi}_{2} \mathrm{~S}_{3}$ solid, meaning that condensation induces chemical reaction as well as physical processes.

$$
\begin{aligned}
& \Delta \mathrm{H}_{\mathrm{f} 298}^{\circ} \mathrm{CdS}(\mathrm{g})=-45.5 \mathrm{kcal} \mathrm{mole}^{-1} \\
& \text { (Mills, 1974) } \\
& \Delta \mathrm{H}_{\mathrm{f} 298}^{\circ} \mathrm{HgS}(\mathrm{g})=+30.4 \mathrm{kcal} \mathrm{mole}^{-1}
\end{aligned}
$$

increasing atomic atomic number:

$$
\begin{aligned}
& \Delta \mathrm{H}_{\mathrm{f} 298}^{\circ} \mathrm{AgS}(\mathrm{g})=+94.0 \mathrm{kcal} \mathrm{mole}^{-1} \\
& \text { (Thermodata Bank) } \\
& \Delta \mathrm{H}_{\mathrm{f} 298}^{\circ} \mathrm{CdS}(\mathrm{g})=-45.5 \mathrm{kcal} \mathrm{mole}^{-1} \\
& \text { (Mills, 1974) } \\
& \Delta \mathrm{H}_{\mathrm{f} 298}^{\circ} \operatorname{InS}(\mathrm{g})=+55.7 \mathrm{kcal} \mathrm{mole}^{-1} \\
& \text { (Thermodata Bank) } \\
& \Delta \mathrm{H}_{\mathrm{f} 298}^{\circ} \mathrm{SnS}(\mathrm{g})=+26.9 \mathrm{kcal} \mathrm{mole}^{-1}
\end{aligned}
$$

It was concluded that a mistake was made when printing the value for $\mathrm{CdS}(\mathrm{g})$ and the real value should be:

$$
\Delta \mathrm{H}_{\mathrm{f} 298}^{\circ} \mathrm{CdS}(\mathrm{g})=+45.5 \mathrm{kcal} \mathrm{mole}^{-1} .
$$

This value is in complete agreement with the theory of homologous series, and gives $\mathrm{CdS}(\mathrm{g})$ non stable at low temperatures (condensing as Greenokite) just as observed in the silica tube and in the natural incrustation around the sampling place (Fig. 8B). This value also agrees with the laboratory experiments (Ibuki, 1959).

In this case, the modeling could test the validity of thermodynamic data in the data bank.

Lead: In the case of lead chloride $\mathrm{PbCl}_{4}(\mathrm{~g})$, the following two data for the enthalpies of formation were found in the literatures:

$$
\Delta \mathrm{H}_{\mathrm{f} 298}^{\circ} \mathrm{PdCl}(\mathrm{g})=-132.0 \mathrm{kcal} \mathrm{mole}{ }^{-1}
$$

( JANAF, 1973)

or

$$
\begin{aligned}
\Delta \mathrm{H}_{\mathrm{f} 298}^{\circ} \mathrm{PbCl}(\mathrm{g})= & -75.0 \mathrm{kcal} \mathrm{mole}{ }^{-1} \\
& \text { (Barin and Knake, 1973). }
\end{aligned}
$$

Both of values are estimated data and the first one has been used in the calculation. If the second one is used, $\mathrm{PbCl}_{4}(\mathrm{~g})$ is not stable at low 
temperature and lead should exist as either $\mathrm{PbS}$ or $\mathrm{PbSO}_{4}$ as observed in the silica tube. Without repeating all the calculation, it is possible to determine the stability field of $\mathrm{PbS}$ and $\mathrm{PbSO}_{4}$ by comparing temperature and oxygen pressure for inversion of the following reaction:

$$
\mathrm{PbSO}_{4} \rightarrow \mathrm{PbS}+2 \mathrm{O}_{2} .
$$

On the other hand, the oxygen fugacity can be calculated from the gas composition, assuming equilibria for the following two reactions:

$$
\mathrm{H}_{2} \mathrm{O}=\mathrm{H}_{2}+1 / 2 \mathrm{O}_{2}
$$

where

$$
\mathrm{P}_{\mathrm{O}_{2}}^{1 / 2}=\mathrm{K}_{2} \cdot \frac{\mathrm{P}_{\mathrm{H}_{2} \mathrm{O}}}{\mathrm{P}_{\mathrm{H}_{2}}}
$$

and

$$
\mathrm{SO}_{2}+\mathrm{H}_{2}=\mathrm{H}_{2} \mathrm{~S}+\mathrm{O}_{2}
$$

where

$$
\mathrm{P}_{\mathrm{O}_{2}}=\mathrm{K}_{4} \cdot \frac{\mathrm{P}_{\mathrm{SO}_{2}} \cdot \mathrm{P}_{\mathrm{H}_{2}}}{\mathrm{P}_{\mathrm{H}_{2} \mathrm{~S}}}
$$

$\mathrm{K}_{\mathrm{i}}$ is the equilibrium constant for $\mathrm{i}^{\text {th }}$ reaction at the fumarole temperature. The comparison between these calculated oxygen fugacities and the inversion oxygen pressures of the sulfate/sulfide reaction leads to conclude that $\mathrm{PbS}$ is stable at temperature higher than $550 \mathrm{~K}\left(277^{\circ} \mathrm{C}\right)$ and $\mathrm{PbSO}_{4}$ is stable at lower temperature (Table 1).

These calculations confirmed the observations made in the tubes at several volcanoes where lead condenses at around $480-400^{\circ} \mathrm{C}$ as galena: $\mathrm{PbS}$ associated with $\mathrm{Bi}$ and $\mathrm{Sn}$, and at about 450 and $400^{\circ} \mathrm{C}$ as sulfosalts of lead and bismuth (Bernard, 1985). In this and previous cases, the modeling and observations served to check thermodynamic data (Fig. 8B).

\section{Testing The Model}

The model is valid only when it represents the natural system. The results of calculation were compared with the deposits observed on the tube wall and in the soil incrustations. The data calculated in modeling are also compared with the results obtained from the analysis of the
Table 1. Inversion $\mathrm{P}_{\mathrm{O}_{2}}$ for reaction (1): $\mathrm{PbSO}_{4}$ $\rightarrow \mathrm{PbS}+2 \mathrm{O}_{2}$

\begin{tabular}{ccccc}
\hline $\mathrm{T}(\mathrm{K})$ & 400 & 500 & 600 & 700 \\
\hline $\mathrm{P}_{\mathrm{O}_{2}}(\mathrm{~atm})$ & $3.67 \times 10^{-45}$ & $1.95 \times 10^{-34}$ & $2.65 \times 10^{-27}$ & $3.3 \times 10^{-22}$ \\
\hline
\end{tabular}

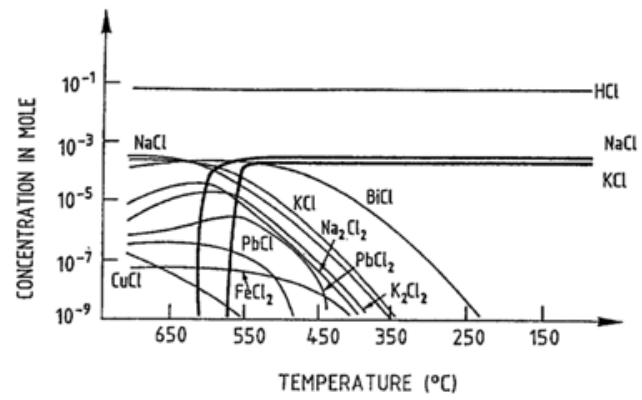

Fig. 9. Chlorine behaviour: Chlorine is present as $\mathrm{HCl}$ whose concentration is high enough not to be affected by its combination with the different metals. Chlorine is associated with the metals in the gas phase and condenses with sodium and potassium.

deposits on tube walls and the natural incrustations (Fig. 7). These results show that temperatures of condensation obtained by the two methods agree but some observed compounds were not obtained by calculations. For example, silica is observed at the same temperature in the calculation than in the tube but with a different formula. The data bank contains only the compounds of which thermodynamic constants are known, and usually their formula are simpler than the minerals found in natural systems.

Considering the global results, it is not possible to show all the results on a single diagram, but it will be easier to analyse them step by step taking the examples of only few elements but keeping in mind that they have been calculated together.

The example of bismuth is shown in Fig. 8c. The calculation shows that bismuth condenses as $\mathrm{Bi}$ (solid) but $\mathrm{BiCl}$ in the gas phase changes to $\mathrm{Bi}_{2} \mathrm{~S}_{3}$ (solid) meaning that condensation induces a phase change and chemical reaction. Consequently, we need to consider $\mathrm{Cl}$ and $\mathrm{S}$ chemistry to discuss the $\mathrm{Bi}$ chemistry in the volcanic gas. Similar conclusion was obtained for lead and cadmium (Figs. 8A and B). 
The chlorine behaviour is shown in Fig. 9. Chlorine is essentially present as $\mathrm{HCl}$ whose concentration is high enough not to be affected by its combination with metals. Chlorine forms complexes with many metals in the gas phase but condenses only with sodium and potassium.

The agreement between the observed and calculated temperatures of condensation is fairly good at high temperature. When the temperature decreases, under $700^{\circ} \mathrm{C}$, the observed temperature is always larger than the calculated temperature. Since the tube is short (one meter) and the gas flow is quite fast, this difference of a few $\mathrm{cm}$ on the tube wall can be due to an error on the temperature measurements. But considering the general trends of the calculated and observed results, we can conclude that they are in a good agreement and the reactions are not far from equilibrium.

The eruption of Mt. St Helens was extensively studied using the best set of geophysical and geochemical methods (Casadevall and Greenland, 1981; Casadevall et al., 1981). Prediction of some small explosions following the May 18 th 1980 big burst were successfully made using the main components of the gas phase: carbon and sulfur (Casadevall et al., 1983). Calculation on thermodynamic equilibria showed the mixing between magmatic volatiles and hydrothermal fluids (Gerlach and Casadevall, 1986).

Other studies described the detection of gas or metals such as mercury or zinc in the volcanic plume as a magmatic signature (Varekamp and Busek 1981; Phelan et al., 1982; Overbeck et al., 1982). In these cases elements was studied separately: the present modeling shows the evolution of the complete gas system.

\section{Conclusions}

Field gas chromatograph measurements, combined with analyses obtained from caustic soda bottles have been qualified as "highest quality analytical data"' (Gerlach and Casadevall, 1986). The silica tube method provides understanding of the condensation temperature of magmatic gases in a closed system without dilution by the
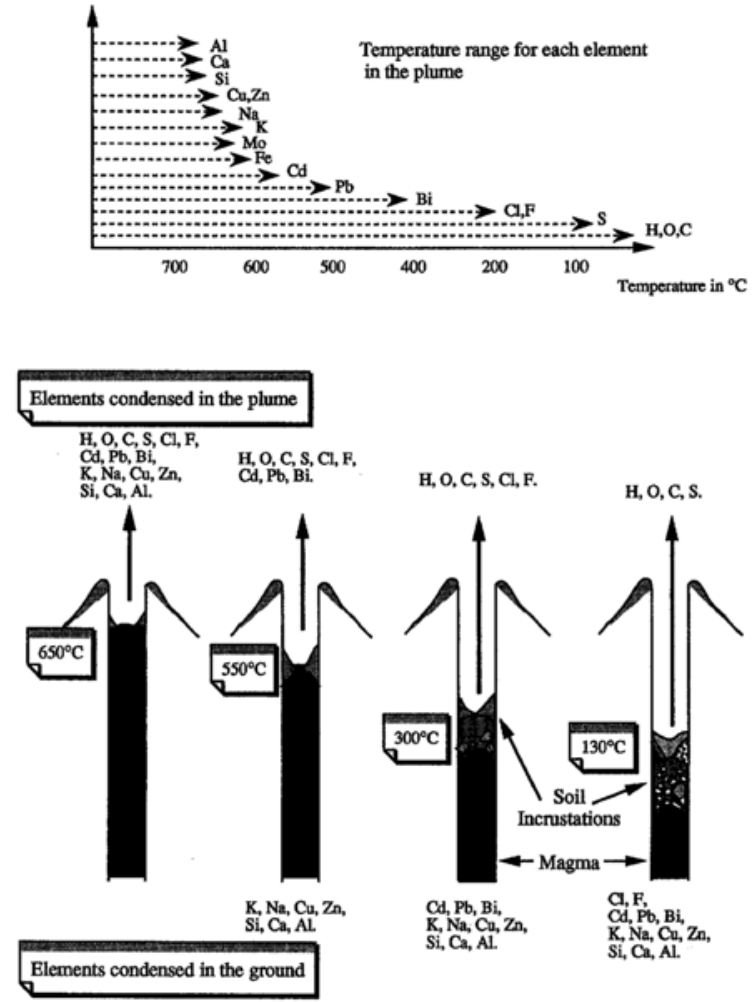

Fig. 10. Chart showing the emission temperature of the elements used for Mt. St Helens modeling (upper diagram) and a new concept for volcano monitoring using the chemical composition of aerosols (lower diagram).

atmosphere. Based on the result of Mt. St Helens gas modeling, a new method for volcano monitoring is proposed using the chemical composition of aerosols. Since the temperature of fumaroles control the emission of elements to the atmosphere (Figs. 8 and 9), the composition of aerosols should reflect the temperature of the outlet (Fig. 10). This model can be used to determine the emission temperature of the volcanic gases from the analysis of elements in the plume. The model is also applicable to estimate the temperature and the composition of the gases entering hydrothermal system or participating in ore deposits in the basement of the volcano.

The trends presented here have been known since last century when different authors discussed the correlation between the temperature of fumaroles and composition of gas and 
sublimates based on magmatic gas differentiation and condensation in the ground (Sainte Claire Deville, 1855; Krauskopf, 1957; Ellis, 1957; Iwasaki et al., 1963). Their empirical conclusions are now confirmed in this study. In our method we consider the solid phases in two independent ways: the field experiments in the silica tube and the computer modeling. The field results are used in a first step to validate the modeling, but the model calculation is independent of the tube results.

The model predicts the behaviour of not only the main components but also the minor species which were not accessible before. This approach is not only restricted to the volcanic gas studies but also can be applied in any high temperature reactive gas reactor to simulate cooling reactions. The analytical and modeling procedures have been tested and is used now in some industrial high temperature gas processes as well as low temperature gas system analysis (Tazieff $e t$ al., 1986; Le Guern, 1988).

The field gas chromatograph confirmed the calculation by Matsuo (1962): both $\mathrm{H}_{2} \mathrm{~S}$ and $\mathrm{SO}_{2}$ exist in magmatic gases. The complete modeling would have allowed detection of a magmatic signature at the Soufriere of Guadaloupe, during the main explosions, as demonstrated at $\mathrm{Mt}$. St Helens. (Le Guern et al., 1980 b; Casadevall 1983; Varekamp and Busek, 1981; Phelan et al., 1982). Discrimination of magmatic activity from phreatic activity would be possible at the initial stage of an eruption by sampling the plume from the distance.

Acknowledgments-Professor S. Matsuo, was a kind of "great father" of the field gas chromatograph. He shared with us not only his ideas but also his warm personality. The building of the prototypes was supported by $\mathrm{H}$. Tazieff, ANVAR, CNRS and CEA. The technical aspects of the instrumentation was solved by A. Nohl, P. Bicocchi and R. M. Chevrier. We wish to thank H. Shinohara, T. M. Gerlach and two anonymous reviewers who improved the quality of this manuscript.

\section{REFERENCES}

Barin, I. and Knake, O. (1973) Thermochemical Properties of Inorganic Substances. Springer Verlag.

Bernard, A. (1985) Les mécanismes de condensation des gaz volcaniques (chimie, minéralogie et équilibres des phases condensées majeures et mineures). Thèse à l'université Libre e Bruxelles 2 tomes, $412 \mathrm{pp}$.

Bernard, A. and Le Guern, F. (1986) Condensation of volatile elements in high temperature of Mount St Helens. J. Volcanol. Geotherm. Res. 28, 91-105.

Casadevall, T. J. and Greenland, L. P. (1981) The chemistry of gases emanating from Mount St Helens, May-September 1980. U.S. Geol. Survey Prof. Paper 1250, 221-226.

Casadevall, T. J., Johnston, D. A., Harris, D. M., Rose, W. I., Malinconico, Jr., Stoiber, R. E. and Bornhorst, T. J. (1981) $\mathrm{SO}_{2}$ emission rates at Mount St Helens from March 29 through December 1980. U.S. Geol. Survey Prof. Paper 1250, 193200.

Casadevall, T. J., Rose, W. Greeland, L. P., Ewert, J., Wunderman, R. and Symonds, R. (1983) Gas emissions and the eruptions of Mount St Helens trough 1982. Science 221, 1383-1385.

Charuau, J. (1982) Etude du dépôt des particules dans les conduits. Optimisation des tubes de prélèvements d'aérosols radioactifs. Rapport CEAR-5158, Service de documentation CEN Saclay 91191 Gif sur Yvette Cedex France.

Chevrier, R. M. and Le Guern, F. (1982). Prélèvements et analyses de condensats de fumerolles sur volcans actifs: Soufrière de la Guadeloupe (1976-1977), Pouzzoles et Vulcano (Italie) 1978. Bull. Volcanol. 45-3, 173-178.

Cheynet, B. (1978) These I.N.P. Grenoble France.

Cheynet, B. (1985) Thermodata: système intégré d'information en thermodynamique et physicochimie inorganique. international meetings on phase equilibrium data. Paris Sept. 1985 ITODYS-Univ. Paris.

Ellis, A. J. (1957) Chemical equilibrium in magmatic gases. Am. J. Sci. 255, 416-431.

Elskens, I., Tazieff, H. and Tonani, F. (1969) A new method for volcanic gas analyses in the field. Bull. Volcanol. T XXXII 3, 523-574.

Gantes, M., Sabroux, J. C. and Vitter, G. (1983) Chemical sensors for monitoring volcanic activity. Forcasting Volcanic Events (H. Tazieff and J. C. Sabroux eds.) Elsevier 28, 409-424.

Gerlach, T. M. and Nordlie, B. E. (1975) The C-O-H$\mathrm{S}$ gaseous system Part 1: Composition limits and trends in basaltic gases; part 2: temperature, atomic composition and molecular equilibrium in volcanic 
gases. Am. J. Sci. 275, 353-394.

Gerlach, T. M. and Casadevall, T. J. (1986) Evaluation of gas data at Mount St Helens 1980, 1982. J. Volcanol. Geotherm. Res. 28, 107-140.

Giggenbach, W. F. (1975) A simple method for collection and analysis of volcanic gas samples. Bull. Volcanol. 39, 132-145.

Giggenbach, W. F. and Le Guern, F., (1976) The chemistry of magmatic gases from Erta Ale Ethiopia. Geochim. Cosmochim. Acta 40, 25-30.

Heald, E. F. and Naughton, J. J. (1962) Calculation of chemical equilibria in volcanic systems by means of computers. Nature 193, 642-644.

Heald, E. F., Naughton, J. J. and Barnes, I. L. (1963) The chemistry of volcanic gases 2: use of equilibrium calculations in the interpretation of volcanic gas samples. J. Geophys. Res. 68, 545-557.

Ibuki, S. (1959) On the crystal growth of cadmium sulphide. J. Phys. Soc. Japan 14, 1181-1184.

Iwasaki, I., Ozawa, T., Oshida, M., Katsura, T., Iwasaki, B. and Kamada, M. (1963) Nature of volcanic gases and volcanic eruptions. Bull Volcanol. 26, 73.

Iwasaki, I. (1971) Chemical surveillance and prediction of volcanic activity. The surveillance and prediction of volcanic activity. A review of methods and techniques. (U.N.E.S.C.O., Paris 8, Earth Sciences) pp 131-137.

Jaggar, T. A. (1917) Volcanic investigations at Kilauea. Am. J. Sci. 261, 131-137.

JANAF (1973) Thermochemical Tables, Dec. 1973.

Jedwab, J. (1975) A method of extraction and analysis of possible cosmic particles from manganese nodules. Meteoritics 10, 133-240.

Krauskopf, K. B. (1957) The heavy metal content of magmatic vapor at $600^{\circ} \mathrm{C}$. Econ. Geol. 52, 786807.

Le Guern, F. and Gerlach, T. M. (1979) High temperature gases from Merapi Volcano, Indonesia: Application of a new technique for field gas measurements. Pacific Northwest American Geophysical Union meeting Bend Oregon 17-18 Sept. 1979.

Le Guern, F., Carbonnelle, J. and D'Amore, F. (1980 a) Temperature and heat flow measurements in a fumarolic area: Vulcano Island (Italy). Bull Volcanol. 43, 569-575.

Le Guern, F., Bernard, A. and Chevrier, R. M. (1980 b) Soufriere of Guadeloupe 1976-1977. Eruption, mass and energy transfer and volcanic health hazards. Bull. Volcanol. 43, 577-593.

Le Guern, F. and Faivre-Pierret, R. X. (1982). Différenciation de l'émanation magmatique: réaction $\mathrm{H}_{2} \mathrm{~S}+\mathrm{SO}_{2}$ dans les gaz volcaniques, Vulcano (Italie) 1923-1979. Bull. Volcanol. 45, 179-190.

Le Guern, F. and Bernard, A. (1982 a) A new method for sampling and analysing volcanic sublimates, application to merapi Volcano Java. J. Volcanol. Geotherm. Res. 12, 133-146.

Le Guern, F. and Bernard, A. (1982 b) Etude des mecanismes de condensation des gaz magmatiques, exemple de l'Etna (Italie). Bull. Volcanol. 45, 161166.

Le Guern, F., Nohl, A. and Bicocchi P., (1982 a) Field measurements of volcanic gases, Vulcano Island (Italy), Kilauea (Hawai, USA), Merapi ( Java Indonesia). Bull. Volcanol. 45, 229-233.

Le Guern, F., Tazieff, H. and Faivre, Pierret, R. (1982 b) An example of health hazard: people killed by gas during a phreatic eruption Dieng plateau (Java), Indonesia, February 20th 1979. Bull. Volcanol. 45-2, 153-156.

Le Guern, F., Gerlach, T. M. and Nohl, A. (1982 c) Field gas chromatograph analyses of gases from a glowing dome at Merapi Volcano, Java, Indonesia, 1977, 1978, 1979. J. Volcanol. Geotherm. Res. 14, 223-245.

Le Guern, F. (1985) Assistance pour l'étude du comportement des volages et effluents gazeux d'un four de verrier. Rapport confidentiel: Saint Gobain Recherche, 39 Quai Lucien Lefranc 93304 Aubervilliers France.

Le Guern, F. (1988) Ecoulements gazeux réactifs à hautes températures, mesures et modélisation. Thèse de doctorat d'état, Université de Paris VII, 314pp.

Matsuo, S. (1962) Establishment of chemical equilibrium in the volcanic gas obtained from the lava lake of Kilauea. Bull. Volcanol. 24, 61.

Mills, K. C. (1974) Thermodynamic data for inorganic sulphides selenides and tellurides. Butterworth and co pp. 845 .

Naughton, J. J., Heald, E. F. and Barnes, I. L. Jr. (1963) The chemistry of volcanic gases. 1 Collection and analysis of equilibrium mixture by gas chromatography. J. Geophys. Res. 68, 539-544.

Naughton, J. J., Lewis, V. A., Hammond, D. and Nishimoto, D. (1974) The chemistry of sublimates collected directly from lava fountains at Kilauea Volcano, Hawaii. Geochim. Cosmochim. Acta 38, 1679-1690.

Nordlie, B. E. (1971) The composition of magmatic gas of Kilauea and its behaviour in the near surface environment. Am. J. Sci. 27, 417-463.

Overbeck, V. R., Farlow, N. H., Fong, W., Snetsinger, K. G., Ferry and G. V. Hayes, D. M. (1982) Mount St Helens aerosols evolution. Geophys. Res. Lett. 9, 1089-1092.

Phelan, J. M., Finnegan, D. L., Ballantine, D. S., Zoller, W. H., Hart, M. A. and Moyers, J. L. (1982) Airborne aerosols measurements in the quies- 
cent plume of Mount St Helens: September 1980. Geophys. Res. Lett. 9, 1093-1096.

Sabroux, J. C. (1979) Equilibre thermodynamique en phase gazeuse volcanique. Hautes Températures et Sciences de la Terre (Editions du CNRS France ISBN 2-222-02619-9), 37-46.

Sabroux, J. C. and Zettwoog, P. (1977) Aide apportee à la prévention civile par la méthode thermodynamique lors de la crise de la Soufrière de la Guadeloupe en 1976. Rapport Commissariat à l'Energie atomique. Institut de protection Nucléaire CEA IPSN STEPAM Fontenay aux Roses $\mathrm{BP}^{\circ}{ }^{\circ} 6$. France.

Sainte Claire Deville, Ch. (1855) Observations sur la nature et la distribution des fumerolles dans l'éruption du Vésuve ler Mai 1855. Mallet imprimeur 55 Quai des Augustins Paris.

Symonds, R. B. (1985) Transport and enrichment of elements in high temperature gases at Merapi volcanoe, Indonesia. Ph. D. Thesis, Michigan Technological University USA pp 101.

Symonds, R. B., Rose, W. I., Reed, M. H., Lichte, F.
E. and Finnegan, D. L. (1987) Volatilisation, transport and sublimation of metallic and non metallic elements in high temperature gases at Merapi Volcano, Indonesia. Geochim. Cosmochim. Acta 51, 2083-2101.

Tazieff, H. and Tonani, F. (1963) Fluctuations rapides et importante de la phase gazeuse eruptive. $C . R$. Acad. Sc. Paris 274, 1003-1006.

Tazieff, H., Faivre-Pierret, R. X., Le Guern, F. and Chevrier, R. M. (1986) La Catastrophe de Nyos République du Cameroun. Rapport Ministère de la Coopération. Contribution CFR $\mathrm{N}^{\circ} 811$ CNRS 91190 Gif sur Yvette, 76pp.

Tonani, F. (1971) Concepts and techniques for the geochemical forecasting of volcanic eruptions. The surveillance and prediction of volcanic activity. A review of methods and techniques. (U.N.E.S.C.O., Paris, 8 Eatrh Sciences) pp 145-166.

VareKampf, C. J. and Buseck, P. R. (1981) Mercury emission from Mount St Helens during September 1980. Nature 293, 555-556. 